specific recommendations for a uniform policy of infection control (BTS Newsletter, winter 1988)

We thank Keymed, Surgikos, and the Sanatorium Society for their support.

1 Department of Health and Social Security. Disinfection of endoscopes potentially contaminated by mycobacterium species. Safety Information Bulletin $1986 ; 28$
2 Working Party of British Society of Gastroenterologists. Cleaning and disinfecion of equipment for gastrointestinal flexible endoscopy. Interim recommendations. Gut 1988;29:1134-51.

3 Centers for Disease Control. Recommendations for prevention of HIV transmission in health care settings. MMWR 1987;36:25.

4 Hanson PJV, Jeffries DJ, Batten JC, Collins JV. Infection control revisited: dilemma facing today's bronchoscopists. Br Med f 1988;297:185-7.

(Accepted 7 February 1989)

\section{Carpal tunnel syndrome and type of dialysis membrane}

\author{
J Chanard, P Bindi, S Lavaud, O Toupance, \\ H Maheut, F Lacour
}

Service de Néphrologie, Centre Hospitalier et Universitaire, Hôpital Maison Blanche, 51092 Reims Cédex, France $\mathrm{J}$ Chanard, MD, professor of nephrology

$\mathrm{P}$ Bindi, MD, resident S Lavaud, MD, hospital practitioner

O Toupance, MD, hospital practitioner

\section{Clinique Chirurgicale} Mutualiste, 51100 Reims H Maheut, MD, consultant nephrologist

F Lacour, MD, consultant nephrologist

Correspondence to: Professor Chanard.

Br Med f 1989;298:867-8 operation. patients.
The carpal tunnel syndrome is commonly seen in patients who have received haemodialysis for a long time. ${ }^{12}$ Compression of the median nerve, flexor tenosynovitis, and destructive arthropathies are associated with hypertrophic material, which generally contains amyloid derived from $\beta_{2}$ microglobulin. The pathogenesis of the syndrome is unknown, although possibly the dialysis membrane has an effect. The syndrome has been reported in patients treated with cellulose membranes non-permeable to $\beta_{2}$ microglobulin. The prevalence of the syndrome increases with the duration of dialysis, and nearly all patients treated for more than 18 years require a decompression

Few data have been reported on the occurrence of amyloidosis due to dialysis in patients treated with synthetic membranes permeable to $\beta_{2}$ microglobulin.' Since the early 1970s we have used the highly permeable polyacrylonitrile AN 69 membrane for dialysis. We report the prevalence of the syndrome in our

Patients, methods, and results

Eighty five patients who had received dialysis for more than seven years were entered into the study. Two groups were selected: group 1 comprised 31 patients who had been treated exclusively with AN 69, and group 2 comprised 54 patients who had been treated with cuprophane for an average of 5.7 (SD 3.9) years and subsequently with AN 69. The mean duration of dialysis was $124 \cdot 2(33 \cdot 0)$ months in group 1 and $126.9(28.6)$ months in group 2 . The mean time for which patients had been exposed to the artificial membrane was 5533 (1200) hours and 7580 (1984) hours respectively $(p<0.05)$. The mean age of the groups was 54 (3) and 49 (14), and the mean serum $\beta_{2}$ microglobulin concentration was $49(15) \mathrm{mg} / \mathrm{l}$ and 45 (13) $\mathrm{mg} / \mathrm{l}$

The carpal tunnel syndrome was considered to be present only when a decompression operation was needed, thus avoiding clinical bias by using motor nerve conduction velocity as reduced velocity may be due to uraemic toxicity without entrapment of the median nerve. After 10 years of dialysis only one patient in group 1 had had the operation, compared with 16 in group $2(\mathrm{p}<0.001)$. Amyloidosis derived from $\beta_{2}$ microglobulin was proved in the only patient in group 1 with the syndrome and in eight out of 12 patients in group 2 from whom synovial specimens were available.

Cumulative survival analysis with the Mantel-Cox model applied to the syndrome at the time of operation showed a significant difference $(p=0 \cdot 0118)$ between the two techniques of dialysis. The proportion of patients without the syndrome after 10 years was predicted to be $94 \%(n=18)$ in those treated with AN 69 and $77 \%(n=21)$ in those treated with several membranes; that at 12 years was predicted to be $94 \%$ $(n=8)$ and $61 \%(n=11)$ respectively.

\section{Comment}

The carpal tunnel syndrome was less common in patients treated exclusively with the highly permeable membrane AN 69 than in patients who had been exposed to cuprophane for at least five years. Preliminary studies have indicated a similar trend for juxta-articular cystic bone defects, which have been assumed to be related to amyloidosis derived from $\beta_{2}$ microglobulin. ${ }^{3}$ Except for the type of membrane used and the time for which patients had been exposed to the membrane there were no clinical or biological differences between the two groups.

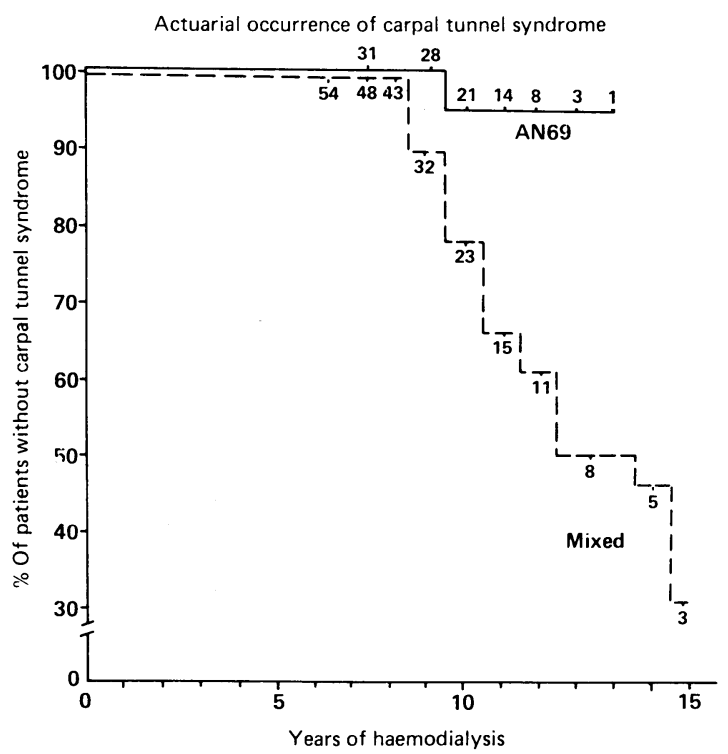

Cumulative percentage of patients without carpal tunnel syndrome, calculated from life tables and survival analysis, in patients given dialysis with AN 69 membrane (— $\longrightarrow$ ) and with several membranes including cellulose membrane $(\div \div \div)$. Figures are numbers of patients. Date of onset of carpal tunnel syndrome was considered to be date of surgery

There are several ways in which AN 69 might prevent or postpone the development of the carpal tunnel syndrome. The concentration of $\beta_{2}$ microglobulin substrate may be insufficient to allow amyloid to form after 10 years of dialysis. With a sieving coefficient of 0.40 for $\beta_{2}$ microglobulin up to about $22.5 \mathrm{~g}$ of the protein is extracted each year, ${ }^{4}$ but despite this serum $\beta_{2}$ microglobulin concentrations remain raised and it would be naive to assume that the serum $\beta_{2}$ microglobulin concentration alone causes amyloidosis in the absence of other promoting factors such as changes in the structure of the precursor protein in the serum ${ }^{5}$ and transformation of the precursor protein in situ by some local process. Alternatively, because AN 69 is more biocompatible than cellulose mem- 
branes it may induce less acute phase reaction. This could play a critical part in preventing or diminishing reactions that favour polymerisation of $\beta_{2}$ microglobulin and generation of amyloid.

1 Bardin T, Zingraff J, Kuntz D, Drüeke T. Dialysis-related amyloidosis. Nephrol Dial Transplant 1986;1:151-4.

2 Brown EA, Arnold IR, Gower PE. Dialysis arthropathy: a complication of long-term treatment with haemodialysis. BrMed J 1986;292:163-6.
3 Vandenbroucke JM, Jadoul M, Maldague B, Huaux JP, Noel H, Van Ypersèle de Strihou C. Possible role of dialysis membranes characteristics in amyloid osteoarthropathy. Lancet 1986;i:1210-1.

4 Chanard J, Lavaud S, Toupance O, Melin JP, Gillery P, Revillard JP. $\beta_{2}$-Microglobulin associated amyloidosis in chronic haemodialysis patients. Lancet 1986; ; 1212

5 Ogawa H, Saito A, Oda O, Nakajima M, Chung TG. Detection of novel $\beta_{2}$-microglobulin in the serum of hemodialysis patients and its amyloidogenic predisposition. Clin Nephrol 1988;30:158-63.

(Accepted 16 December 1988)

\title{
Rat bites and diabetic foot in the West Indies
}

\author{
P Cooles, H Paul
}

\section{Princess Margaret \\ Hospital, Roseau, Dominica, West Indies P Cooles, MRCP, consultant physician H Paul, FRCS, consultant surgeon}

Correspondence to: $\mathrm{Dr}$ Cooles.

BrMed f 1989;298:868
Diabetes mellitus, a disease associated with affluence, is an increasing problem in the West Indies. ${ }^{\prime}$ Diabetic foot is an important cause of morbidity and is often complicated by rat bites. We present four cases of rat bites on a diabetic foot.

\section{Case reports}

The table summarises details of the cases.

Details of four cases of rat bites on a diabetic foot

\begin{tabular}{|c|c|c|c|c|c|c|}
\hline $\begin{array}{l}\text { Case } \\
\text { No }\end{array}$ & $\begin{array}{c}\text { Age } \\
\text { (years) }\end{array}$ & Sex & $\begin{array}{l}\text { Peripheral } \\
\text { neuropathy }\end{array}$ & $\begin{array}{c}\text { Foot } \\
\text { pulses }\end{array}$ & $\begin{array}{l}\text { Length of } \\
\text { hospital stay } \\
\text { (days) }\end{array}$ & $\begin{array}{l}\text { Outcome for } \\
\text { foot }\end{array}$ \\
\hline 1 & 36 & $M$ & Yes & Yes & 23 & Saved \\
\hline 2 & 70 & $F$ & Yes & No & 30 & Amputated \\
\hline 3 & 73 & $\mathrm{~F}$ & Yes & No & 7 & Saved \\
\hline 4 & 50 & $M$ & Yes & Weak & 27 & Saved \\
\hline
\end{tabular}

Case 1-An insulin dependent diabetic woke one morning to see a rat eating his left hallux and second toe. He could not feel the bites. Diabetes had been diagnosed four years earlier and peripheral neuropathy one year earlier on the basis of impaired sensation below the knees, absent ankle and knee jerks, and impotence. After two weeks of care by the village nurse he was referred to hospital. Culture of material from a wound swab grew a $\beta$ haemolytic streptococcus. $\mathrm{He}$ was treated with oral cloxacillin and metronidazole, and the wound was cleaned daily. The wound healed satisfactorily, and he was discharged taking 80 units isophane insulin daily in two doses.

Case 2-A woman presented one week after waking with an extensive rat bite on her left hallux. She was not known to be diabetic but had noticed polyuria for several months. Her blood glucose concentration on admission was $19 \mathrm{mmol} / 1$. Her toe was gangrenous, and there were no palpable foot pulses. Sensation in both feet was severely impaired, and both ankle and knee jerks were absent. Culture of material from a wound swab grew a proteus. Amputation below the knee was performed 10 days after admission, and she was discharged taking chlorpropamide $250 \mathrm{mg}$ daily.

Case 3-A woman awoke with a large rat bite on her left hallux. She had had diabetes for 13 years, which had been controlled with oral chlorpropamide. Amputation below the right knee had been performed two years earlier. After two weeks of care by the village nurse she was sent to hospital. Foot pulses and ankle and knee jerks were absent. Sensation was severely impaired below the knee. Material from a wound swab was sterile. When she was discharged the wound was healing satisfactorily with daily cleaning and chlorpropamide $250 \mathrm{mg}$ daily.

Case 4-A man was referred two weeks after waking to find his feet bleeding from multiple painless rat bites. He had been diabetic for 13 years but had not attended a clinic for over a year. He had absent knee and ankle jerks, impaired sensation in his feet, and weak foot pulses. Material from wound swabs was sterile. His wounds healed with conservative management, and he was discharged taking 30 units insulin zinc suspension daily.

\section{Comment}

Rat bites can have serious consequences and even cause death. ${ }^{2}$ Clinton estimated that there were at least 14000 rat bites a year in the United States, ${ }^{2}$ and Deoras reported 20000 admissions for rat bites to hospitals in Bombay each year. ${ }^{3}$ Most bites occur during sleep, and victims usually wake and frighten the rat away, except in the case of small infants or the very infirm. People with peripheral neuropathy, however, do not feel the bites, and the rat can continue to feed undisturbed.

Five per cent of adult Dominicans are diabetic ( $R$ Fortune, unpublished data), and the ratio of rats to humans in Dominica may be as high as five to one (B Xavier, personal communication). Housing conditions are poor, largely owing to hurricane David, which in 1979 left three quarters of the people homeless. Diabetic foot is a well recognised problem. ${ }^{4}$ The combination of a high population of rats, poor housing, and a high prevalence of diabetes means that rat bites commonly cause lesions on diabetic feet. The incidence of such lesions is underestimated as patients may not volunteer or even realise that they have been caused by rats. We advise all of our diabetic patients to cover their feet while asleep and seek immediate medical help for any foot lesion.

1 Walrond EW, Jordan OW. Suggestions for a new approach to diabetes. Cajanus
1985;18:127-30 (Caribbean Food and Nutrition Institute, Jamaica).
2 Clinton JM. Rats in urban America. Public Health Rep 1969;84:1-7.
3 Deoras PJ. Some observations on the probable damage caused by rats in
Bombay. Indian fournal of Entomology 1966;28:543-7.
4 Alberti KGGM, Hockaday TDR. Diabetic foot disease. In: Weatherall DJ,
Ledingham JGG, Warrell DA, eds. Oxford textbook of medicine. Oxford:
Oxford University Press, 1984:9.37-8.
(Accepted 15 September 1988) 